\title{
ARTICLE
}

\section{Retention of uranium in cement systems: effects of cement degradation and complexing ligands}

\author{
Michael Ochs ${ }^{\mathrm{a}^{*}}$, Bas Vriens ${ }^{\mathrm{a}}$ and Yukio Tachi ${ }^{\mathrm{b}}$ \\ ${ }^{a}$ Arcadis Switzerland Ltd, Ifangstrasse 11, CH-8952 Schlieren/Zürich, Switzerland; ${ }^{b}$ Japan Atomic Energy Agency (JAEA), 4-33 \\ Muramatsu, Tokai, Ibaraki, 319-1194, Japan
}

\begin{abstract}
The clean-up activities related to the accident at the Fukushima nuclear power plant give rise to several types of wastes containing cementitious materials as well as substances that can influence radionuclide migration, especially organic complexing substances, boron, and chloride salts. The present study focuses on a methodology, based on available literature information, for quantifying the retention behavior of uranium (VI) in cement materials of different degradation states and in the presence of organics, boron, and salts. To account for the many variables defining uranium uptake in cement systems a stepwise approach is proposed and illustrated: 1) definition of conditions and $U$ speciation in each relevant degradation state, 2) assessment of $\mathrm{U}(\mathrm{VI})$ uptake processes based on a critical review of literature information, 3) $\mathrm{K}_{\mathrm{d}}$ setting on the basis of original experimental data that are consistent with the identified processes and speciation, 4) assessment of ligand effects based on data preferably from ternary systems, or from speciation and analogue information.
\end{abstract}

Keywords: Fukushima Daiichi nuclear power plant; cement; concrete; sorption reduction facto; uranium organic ligands; ISA

\section{Introduction}

Several types of wastes containing concrete materials are being generated in the context of the clean-up and decommissioning activities following the accident at the Fukushima nuclear power plant. Additional cementitious materials are expected to be present in repository components related to the disposal of these wastes.

The safety of any radioactive waste disposal system depends on the prevention or sufficient retardation of radionuclide transport to the biosphere by waste matrices or engineered barriers. Based on their origin, post-accident wastes from Fukushima differ in their composition from typical nuclear decommissioning wastes and are expected to contain higher levels of substances that can have perturbing effects on retention. In particular, organic complexing substances, boron, and salts are thought to be relevant [1].

In view of the many variables defining the magnitude of uranium uptake (expressed by $\mathrm{K}_{\mathrm{d}}$ ) in cement systems (cement degradation state and mineralogy, $\mathrm{U}$ oxidation state and speciation as a function of conditions, effects of ligands), a stepwise approach is proposed and illustrated for $K_{d}$ setting. Due to the insufficient characterization of post-accident Fukushima wastes, this is done for pessimistic conditions.

*Corresponding author. Email: michael.ochs@arcadis.com

\section{Approach and specific conditions}

\subsection{Approach proposed for quantifying reference $K_{d}$ values and sorption reduction effects}

For the present illustration of quantifying $\mathrm{K}_{\mathrm{d}}$ as well as the effect of complexing ligands, it is generally assumed that these ligands will affect only the radionuclide behavior. The overall geochemical conditions ( $\mathrm{pH}$, major ion concentrations, etc.) are assumed to be buffered sufficiently by solid cement phases. In most environments, cementitious materials are slowly degraded following a typical sequence of degradation states shown schematically in Figure 1.

The methodology followed for conducting the $K_{d}$ setting examples is based on the approaches by [3-8] and consist of the following steps:

1) Definition of conditions (in particular mineralogy and $\mathrm{Ca} / \mathrm{Si}$-ratio of cement phases, and the resulting solution composition) and U speciation for each relevant degradation state.

2) Best possible assessment of U(VI) uptake processes for each degradation state based on a critical review of literature information. This includes identification of uptake processes and of trends of uptake as a function of cement degradation.

3) $K_{d}$ setting on the basis of original experimental data that are consistent with the identified processes and speciation. Preferred are datasets covering several states or applicable to state II, which is most stable. 
4) Assessment of the (maximum) concentration of complexing ligands. Evaluation of sorption reduction effects preferably based on data from ternary systems, or from speciation and analogue information (see [10]).

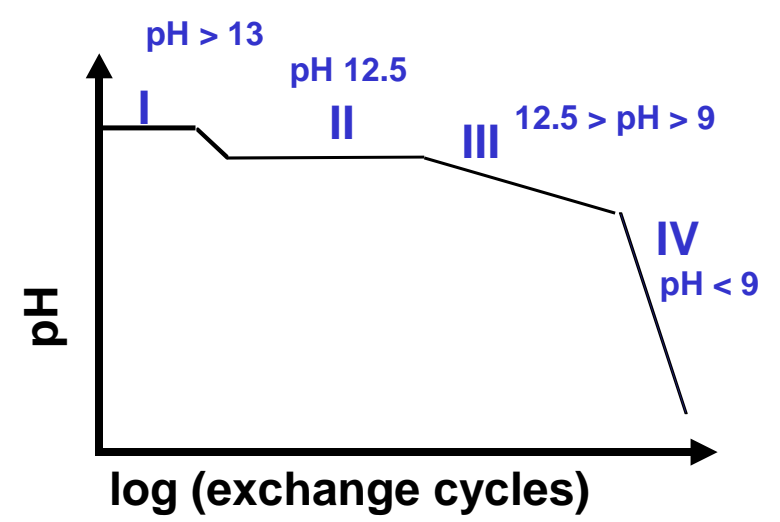

Figure 1. Schematic representation of cement degradation states. Exchange cycles refer to exchanges of porewater volumes. After [2], see also [3] and references therein.

\subsection{Specific conditions considered}

Waste stemming from Fukushima cleanup activities include concrete rubble, sludge from concrete decontamination, and concrete/fuel debris from the reactor. For the present purpose, these materials are treated as normal cementitious material. It is planned to dispose these materials in different cement-based repository types. Degradation states I-III are expected within the relevant overall disposal timeframe. The wastes are expected to contain a range of organic substances, borates, and other salts [1]. To date, no specific information is available regarding concentration and characteristics of these complexing ligands in the various waste types. Therefore, somewhat arbitrary, pessimistic concentration estimates of some model compounds as given in Table $\mathbf{1}$ are used for the present purpose. In lack of any specific information, organics are represented by ISA as a worst-case assumption regarding complexation properties.

Table 1. Pessimistic concentration estimates of model complexing ligands in waste from Fukushima cleanup.

\begin{tabular}{|l|r|r|}
\hline \multirow{2}{*}{ Complexing ligands } & \multicolumn{2}{|l|}{ Concentrations [mol/L] } \\
\cline { 2 - 3 } & high & extremely high \\
\hline Organics $^{1}$ & 0.01 & 0.1 \\
\hline Borates $^{2}$ & 0.01 & 0.1 \\
\hline Salts $^{3}$ & 0.6 & 6 \\
\hline
\end{tabular}

Organics are represented by ISA (pessimistic assumption)

As $\mathrm{Na}_{2} \mathrm{~B}_{10} \mathrm{O}_{16} \cdot 10 \mathrm{H}_{2} \mathrm{O}$ (Na-pentaborate)

As $\mathrm{NaCl}$ (sea water / sea water concentrated through evaporation)

These values are derived through extremely pessimistic assumptions; for example, it can be practically excluded that all organic ligands will exist as isosaccharinic acid (ISA), and most other organic ligands have weaker complexation properties towards actinides $[7,8]$.

\section{Estimation of reference $K_{d}$ (ligand-free system)}

\subsection{Data situation and uptake mechanisms for U(VI)}

Hydrated cement exerts a strong buffering effect on cement porewater chemistry. As a result, the composition of solutions in contact with HCP is invariably dominated by a few constituents, whose concentration can be predicted for each degradation state, and reliable data from laboratory systems can generally be viewed as representative for in-situ conditions. By considering the $\mathrm{Ca} / \mathrm{Si}$ ratio and solution $\mathrm{pH}$ as master variables, data from different systems can be compared. This is shown in Figure 2 for U(VI).

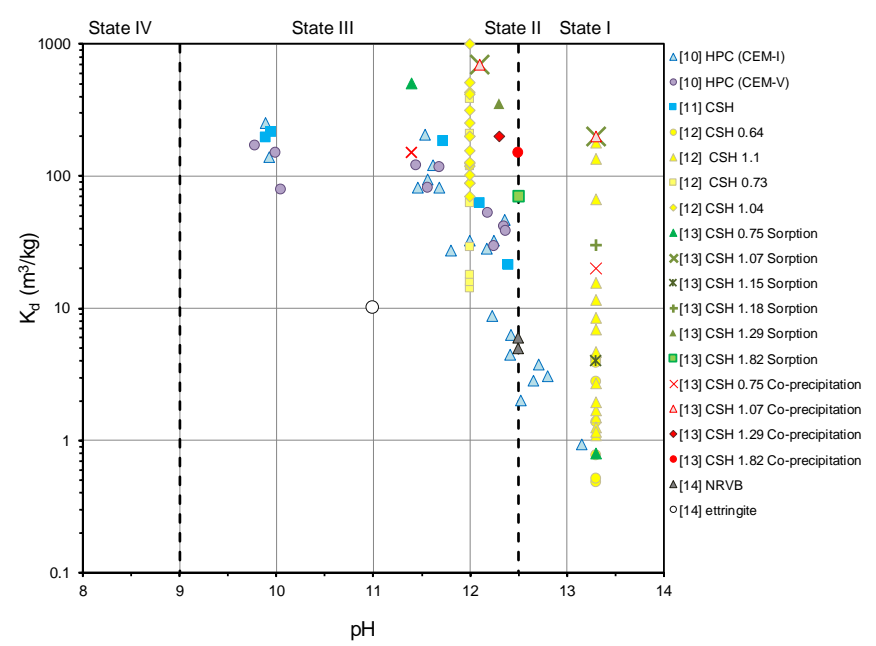

Figure 2. Overview of uptake data for U(VI) on hydrated cement phases corresponding to different degradation states.

It follows from Figure 2 that the assignment of recommended $K_{d}$ values to specific points in the evolution of a repository hinges on the modeling of the cementitious system degradation (in particular on the change in $\mathrm{pH}, \mathrm{Ca} / \mathrm{Si}$ ratio and other mineralogical properties). A somewhat generalized evolution is assumed for the present illustration.

The uptake of U(VI) on hydrated cement phases has been shown to be strong by many studies (Figure 2, see also [3] and references therein), and the data in Figure 2 suggest increasing uptake with degradation.

The nature of the uptake process of U(VI) has been unknown for many years. Initially, it was ascribed to the formation of some U-Ca-Si solid solution [17]. Only recently, sorption and co-precipitation experiments on Ca-Si-hydrates (CSH) with different $\mathrm{Ca} / \mathrm{Si}$ ratio by [13] and [14] allowed to distinguish between U(VI) species incorporated in the CSH structure and sorbed U(VI).

$\mathrm{K}_{\mathrm{d}}$ values determined from both sorption and co-precipitation experiments by [13] and [14] lie within the same range, indicating a similar uptake process. This is supported by recent spectroscopic studies [18,19], which suggest that in $\mathrm{CSH}$, the coordination environment of both surface-bound or incorporated $\mathrm{U}(\mathrm{VI})$ is comparable to that in Ca-uranyl-silicates.

Another important factor for U(VI) uptake appears to be the aqueous speciation of U(VI). Uptake experiments 
by [14] and [15] of U(VI) by CSH with different Ca/Si at different $\mathrm{pH}$, in combination with solubility measurements and speciation calculations (see also [4]) indicate that $\mathrm{U}(\mathrm{VI})$ uptake decreases above $\mathrm{pH} \sim 11$ due to the formation of negatively charged higher hydrolytic species (see below).

\subsection{Reference $K_{d}$}

Definition of recommended $K_{d}$ is mainly based on the clear relationship between uptake and macroscopic variables, especially $\mathrm{pH}$.

The trend of $\mathrm{K}_{\mathrm{d}}$ vs $\mathrm{pH}$ in Figure 2 approximately follows the predicted concentration (see [4]) of the $\mathrm{UO}_{2}(\mathrm{OH})_{3}{ }^{-}$species. Further, the Ca-concentration increases from state I to II, which would also be compatible with increasing uptake (see section 3.1).

Note that the apparently large variation of $\mathrm{K}_{\mathrm{d}}$ at $\mathrm{pH}$ 13.3 and $\mathrm{pH} 12.5$ in the data by [13] is due to the fact that these data were recorded as isotherms, covering a wide range of dissolved U(VI) concentrations. However, it can clearly be seen the isotherm data correspond to the general trend, with the group at $\mathrm{pH} 12.5$ encompassing a range of much higher $\mathrm{K}_{\mathrm{d}}$ than the data group at $\mathrm{pH}$ 13.3.

Assuming uptake to decrease from state III $\rightarrow$ II with a slope of -1 , based on the difference of one $\mathrm{H}^{+}$in the hydrolysis of $\mathrm{UO}_{2}(\mathrm{OH})_{3}{ }^{-}$to $\mathrm{UO}_{2}(\mathrm{OH})_{4}{ }^{2-}$, the difference in $\mathrm{K}_{\mathrm{d}}$ between states II ( $\left.\mathrm{pH} 12.5\right)$ and the beginning of state III ( $\mathrm{pH} \sim 11.5)$ should correspond roughly to a factor of 10. From the slope of experimental data in Figure 2, a range of about $10-35 \mathrm{~m}^{3} / \mathrm{kg}$ can be estimated for state II (with a corresponding range of $1-3.5 \mathrm{~m}^{3} / \mathrm{kg}$ for state I). From these ranges, a $K_{d}$ of $2 \mathrm{~m}^{3} / \mathrm{kg}$ is recommended for state $I$ and a $K_{d}$ of $20 \mathrm{~m}^{3} / \mathrm{kg}$ is recommended for state II (see Table 2).

For state III, the experimental data as well as the proposed trend of uptake as a function of conditions would suggest a similar $\mathrm{K}_{\mathrm{d}}$ value as for state II at the initial phase of phase III, and a significantly higher $\mathrm{K}_{\mathrm{d}}$ $\left(>100 \mathrm{~m}^{3} / \mathrm{kg}\right)$ in the range of $\mathrm{pH} 11-9$. To acknowledge the fact that relatively few data are available for state III, and that the evaluation of solid and aqueous phase conditions is also more uncertain for state III, the same value as for state II $\left(20 \mathrm{~m}^{3} / \mathrm{kg}\right)$ is conservatively recommended for the entire state III (Table 2).

\section{Estimation of sorption reduction effects}

\subsection{Organic substances (ISA)}

Speciation calculations indicate that the speciation of U(VI) would be entirely dominated by ISA-complexes [9]. This indicates that ISA may have a significant effect but does not allow to draw quantitative conclusions regarding sorption reduction.

To our knowledge, only Pointeau et al. ([11,12]) conducted experiments in the ternary system U(VI)-ISA-cement (Figure 3). They considered two sets of conditions corresponding approximately to state I and to state III, and ISA concentrations in the range of
$1 \times 10^{-5} \mathrm{M}$ to about $6 \times 10^{-3} \mathrm{M}$. Sorption reduction effects are estimated directly from their data.

Assuming a linear trend of sorption reduction as a first approximation, it can be estimated that U(VI) uptake at [ISA] $=0.01 \mathrm{M}$ and $0.1 \mathrm{M}$ will be about 10 -fold and 100-fold lower than in an ISA-free system. Sorption reduction may be less pronounced in state I, but it is recommended to consider 10 -fold to 100 -fold decrease for all states.

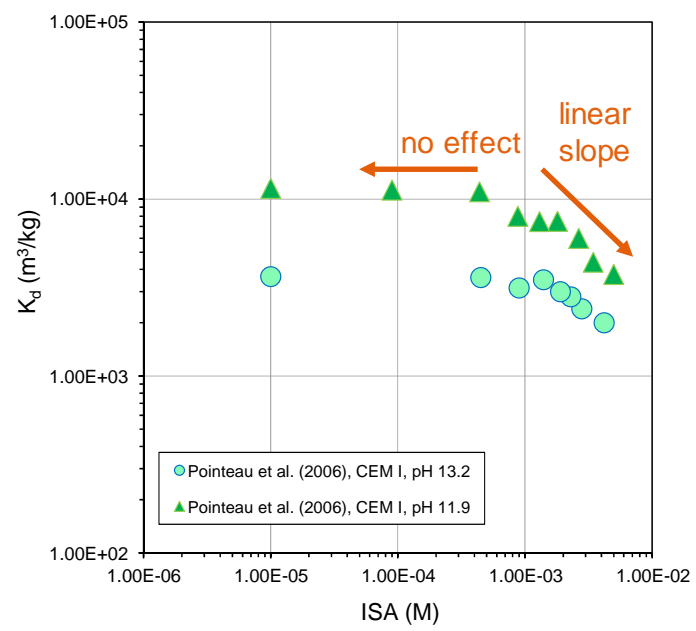

Figure 3. Uptake of U(VI) on hydrated cement paste in state I and state III as a function of ISA concentration. Data by [21].

\subsection{Borate and salt ( $\mathrm{NaCl})$}

Very little information is available on the interaction of borates with actinides in cement solutions, and no information is available regarding effects on $\mathrm{U}(\mathrm{VI})$ uptake. To our knowledge only some work regarding effects on the solubility limit in WIPP brine solutions is available. At $\mathrm{pH} \sim 9,0.05 \mathrm{M}$ tetraborate was found to increase U(VI) solubility by about two orders of magnitude [20], but no information is available for higher $\mathrm{pH}$ or for an effect on sorption. To our knowledge, there is also no information available regarding the effect of borate species on radionuclide sorption on any other mineral phase (e.g., clays or oxides).

Due to the lack of relevant information, an arbitrary decision is made at this point with regard to the sorption reduction effect of borate. As a pessimistic approach, the complexation and thus the sorption reduction effect of borate is set identical to the effect of ISA. As an approximation, the effects at [ISA] $\sim 0.01$ and [borate] $\sim 0.01 \mathrm{M}$ at set equal. Assuming a constant effect as a function of borate concentration gives a 10 -fold decrease again in $\mathrm{K}_{\mathrm{d}}$ for [borate] $0.1 \mathrm{M}$.

For $6 \mathrm{M}$ saline solutions, speciation calculations indicate no important formation of U-chloride complexes. Calculations further show an increase (more likely, would tend to increase $\mathrm{K}_{\mathrm{d}}$ ) or decrease of the stability of $\mathrm{UO}_{2}(\mathrm{OH})_{3}{ }^{-}$in comparison to $\mathrm{UO}_{2}(\mathrm{OH})_{4}{ }^{2-}$, depending on ionic strength correction terms used. Due to the weak interaction of $\mathrm{Na}^{+}$with cement, no strong competition is expected. On the other hand, very high chloride concentrations could alter cement mineralogy. 
A 10-fold decrease strong of $K_{d}$ is therefore cautiously proposed for the $6 \mathrm{M}$ saline solution; no effect is considered for the lower salinities.

\section{Data summary and conclusions}

Recommended $K_{d}$ values are summarized in Table 2. The magnitude of uptake for U(VI) (and other radionuclides) can be estimated well from experimental data. In view of the complexity of uptake processes in hydrated cement systems, recommended $K_{d}$ should be plausible in view of available detailed chemical information on radionuclide speciation and cement degradation as a function of time.

Table 2. Summary of recommended $\mathrm{K}_{\mathrm{d}}$ values (all in $\mathrm{m}^{3} / \mathrm{kg}$ ).

\begin{tabular}{|c|c|c|c|c|c|c|c|}
\hline & reference & \multicolumn{2}{|c|}{ ISA } & \multicolumn{2}{c|}{ Borate } & \multicolumn{2}{c|}{$\mathrm{NaCl}$} \\
\cline { 3 - 8 } & system & $0.01 \mathrm{M}$ & $0.1 \mathrm{M}$ & $0.01 \mathrm{M}$ & $0.1 \mathrm{M}$ & $0.6 \mathrm{M}$ & $6 \mathrm{M}$ \\
\hline state I & 2 & 0.2 & 0.02 & 0.2 & 0.02 & 2 & 0.2 \\
\hline state II & 20 & 2 & 0.2 & 2 & 0.2 & 20 & 2 \\
\hline state III & 20 & 2 & 0.2 & 2 & 0.2 & 20 & 2 \\
\hline
\end{tabular}

Sorption reduction effects due to the presence of complexing substances can be assessed transparently and with reasonable certainty when data from ternary systems (radionuclide-ligand-cement) are available. In other cases, approximations are needed (see [10]); including pessimistic assumptions in case of lacking data. The step-wise approach illustrated here is pragmatic, but provides qualitative arguments and traceability.

At the same time, it needs to be verified that the cement paste itself is stable at high concentrations of organic ligands and salts.

\section{Acknowledgements}

M. Ochs and B. Vriens greatly appreciate funding and collaboration by Japan Atomic Energy Agency.

\section{References}

[1] Atomic Energy Society of Japan, The Fukushima Daiichi Nuclear Accident. Final Report of the AESJ Investigation Committee, Springer, 2015.

[2] U. Berner, Evolution of pore water chemistry during degradation of cement in a radioactive waste repository environment, Waste Management, 12 (1992), pp. 201-219.

[3] M. Ochs, D. Mallants and L. Wang, Radionuclide and metal sorption on cement and concrete, Topics in Safety, Risk, Reliability and Quality, Springer International Publishing Switzerland, (2016).

[4] L. Wang, E. Martens, D. Jacques, P. de Cannière, J. Berry and D. Mallants, Review of sorption values for the cementitious near field of a near surface radioactive waste disposal facility, NIROND TR 2008-23E, ONDRAF/NIRAS (2009).

[5] M. Ochs, L. Vielle-Petit, L. Wang, D. Mallants and B. Leterme, Additional sorption parameters for the cementitious barriers of a near-surface repository, NIROND-TR 2010-06 E, ONDRAF/NIRAS (2011).

[6] E. Wieland and L. Van Loon, Cementitious near-field sorption data base for performance assessment of an ILW repository in Opalinus Clay, Nagra Technical Report NTB 02-20 Nagra, Wettingen, Switzerland (2002).

[7] E. Wieland, Sorption data base for the cementitious near field of L/ILW and ILW repositories for provisional safety analyses for SGT-E2, Nagra NTB 14-08, (2014).

[8] SKB, Waste form and packaging process report for the safety assessment SR-PSU, SKB TR-14-03, Svensk Kärnbränslehantering AB (2014a).

[9] M. Ochs, E. Colàs, M. Grivé, J. Olmeda, I., Campos and J. Bruno, Reduction of radionuclide uptake in hydrated cement systems by organic complexing agents: Selection of reduction factors and speciation calculations, SKB R-14-22, (2014).

[10]Y. Tachi and M. Ochs, Sorption parameter setting approaches for radioactive waste disposal considering perturbation effects: sorption reduction factors for organics, Prog. Nucl. Sci. Technol. 5 (2018), pp. 229-232.

[11]I. Pointeau, C. Landesmann, E. Giffaut and P. Reiller, Reproducibility of the uptake of U(VI) onto degraded cement pastes and calcium silicate hydrate phase, Radiochim. Acta 92 (2004), pp. 645-650.

[12]I. Pointeau, C. Landesman, N. Coreau, C. Moisan, P. Reiller, Etude de la rétention chimique des radionucléides $\mathrm{Cs}(\mathrm{I}), \mathrm{Am}(\mathrm{III}), \mathrm{Zr}(\mathrm{IV}), \mathrm{Pu}(\mathrm{IV})$, $\mathrm{Nb}(\mathrm{V}), \mathrm{U}(\mathrm{VI})$ et $\mathrm{Tc}(\mathrm{IV})$ par les matériaux cimentaires degrades, CEA Rapport RT DPC/SECR 03-037 indice A (2004).

[13]J. Tits, T. Fujita, M. Tsukamoto and E. Wieland, Uranium(VI) uptake by synthetic calcium silicate hydrates, MRS Proceedings 1107 (2008) pp. 467-474.

[14]J. Tits, T. Fujita, M. Harfouche, R. Dähn, M. Tsukamoto and E. Wieland, Radionuclide uptake by calcium silicate hydrates: Case studies with Th(IV) and U(VI), PSI Bericht Nr. 14-03. Paul Scherrer Institut, Villigen, Switzerland, (2014).

[15]S. Bayliss, R. McCrohon, P. Oliver, N.J. Pilkington and H.P. Thomason, Near-field sorption studies: January 1989 to June 1991, NSS/R277, AEA-ESD-0353 (1996).

[16]S. Baker, P. Oliver and R. McCrohon, Near-field batch sorption studies - 1992 to 1998, AEAT/ERRA-0345 (2002).

[17]L.P. Moroni and F.P. Glasser, Reactions between cement components and $\mathrm{U}(\mathrm{VI})$ oxide, Waste Management, 15 (1995), pp. 243-254.

[18]J. Tits, G. Geipel, N. Macé, M. Eilzer and E. Wieland, Determination of uranium(VI) sorbed species in calcium silicate hydrate phases: A laser-induced luminescence spectroscopy and batch sorption study, J. Coll. Interface Sci. 359 (2011), 
pp. 248-256.

[19]N. Macé, E. Wieland, R. Dähn, J. Tits and A.C. Scheinost, EXAFS investigation on U(VI) immobilization in hardened cement paste: Influence of experimental conditions on speciation, Radiochim. Acta 101 (2013), pp. 379-389.

[20]J.-F. Lucchini, M. Borkowski, M.K. Richmann and
D.R. Reed, Uranium(VI) solubility in carbonate-free WIPP brine, Radiochim. Acta 101 (2013), pp. 391-398.

[21]I.Pointeau, D. Hainos, N. Coreau and P. Reiller, Effect of organics on selenite uptake by cementitious materials, Waste Management 26 (2006), pp. 733-740. 